Social Sciences, Humanities and Education Journal (SHE Journal)

Volume 1 (2) 61 - 73, May 2020 | ISSN: 2720-9946 (Online)

The article is published with Open Access at: http://e-journal.unipma.ac.id/index.php/SHE

\title{
ACCURACY OF THE TRANSLATION OF CULTURAL WORDS IN THE MAZE RUNNER NOVEL INTO INDONESIAN LANGUAGE
}

Widya Dara Anindya; Universitas Gadjah Mada

Adi Sutrisno; Universitas Gadjah Mada

Soepomo Poedjosoedarmo; Universitas Sanata Dharma

Sigit Ricahyono $\bowtie$; Universitas PGRI Madiun

\begin{abstract}
There have been plenty of studies on translation accuracy, but that focusing on cultural words under-investigated. The current study investigated the translat ion accuracy of The Maze Runner Novel in English by James Dashner into Indonesian by Yunita Candra. As many as 11 cultural words were collected. To measure the accuracy, questionnaires were distributed to 12 translators of at least 1 year of professional experience. The taxonomy devel oped by Pelawi (2014) covering categories of accurate (Ak), less accurate ( KAk), and not accurate ( TAk) was applied. Results show that (Ak) occurs $7 / 64 \%$, (KAk) does $3 / 27 \%$, and (TAk) does $1 / 9 \%$. That a number of the data fall into the category of (KAk) and (TAk) indicate that while cultures share common features (universal), at the same time they contain characteristic features that are unique. It goes, therefore, no cultural expressions can be in total accuracy if they are transplanted into other cultures.
\end{abstract}

Keywords: Accuracy, Translation, Cultural Words, The Maze Runner Novel, Indonesian L anguage

$\bowtie$ ricahyono@yahoo.com

Citation: Anindya, W. D., Sutrisn o, A., Poedjosoedarmo, S., \& Ricahyono, S. (2020). Accuracy of the translation of cultural words in the maze runner novel into indonesian language . Social Sciences, Humanities and Education Journal (SHE Journal), 1(2), 61 - 73. DOI: 10.25273/she.v1i2.6716

\section{(c) $)$ BY-NC-SA}




\section{PENDAHULUAN}

Terjemahan menjadi topik penelitain yang popular sehingga hasil kajian pustaka menunjukkan bahwa topik ini telah banyak dikaji dari banyak perspektif dan banyak disiplin. Salah satu unsur yang menarik masalah terjemahan adalah akurasi. Tim riset terjemahan Bsu Afrikaans, Tswana, Swahili dan Portuguese ke Bsa Inggris menguji akurasi mesin terjemahan Lexica Machine Translation. Simpulan kajian mereka adalah "there are no universally accepted and reliable methods and measures" (Snyman \& Naudé, 2003). Penelitian serupa juga dilakukan oleh Barnett, Palmer \& Al-Deen (1984), Rennie, Engova, \& Bates (2008). Hal yang lebih menarik adalah akurasi dalam menerjemahkan ungkapan-ungkapan budaya. Pada satu sisi, budaya mengandung nilai-nilai universal (cultural universals), tetapi pada sisi lain, budaya itu unik (culture specific) (MichelSchertges, 2019). Apakah nilai-nilai budaya masyarakat mempengaruhi bagaimana masyarakat merespon iklan juga diteliti. Hasilnya nilai-nilai budaya berpengaruh terhadap perilaku masyarakat terhadap iklan . Bagaimana budaya terefleksikan dalam iklan banner online di Tiongkok, Jepang, Korea dan Amerika Serikat juga dikaji dengan merujuk pada konsep budaya Hofstede, Hall, dan Trompenaars \& HampdenTurner. Hasil akhirnya juga budaya berpengaruh terhadap strategi kreatif dalam pemilihan dan penataan konten iklan banner online (Jin, 2010) . Ini artinya, ungkapan-ungkapan budaya tidak mudah dialihkan ke dalam konteks budaya lain. Penelitian ini mefokuskan pada akurasi terjemahan ungkapaungkpan budaya yang terdapat dalam novel The Maze Runner versi bahasa asli
(Bahasa Inggris) oleh James Dashner sebagai teks sumber (TSu) ke dalam Bahasa Indonesia oleh Yunita Candra sebagai teks sasaran (TSa).

\section{Keakuratan (Accuracy) Terjemahan}

Dikarenakan penerjemahan merupakan kegiatan memindahkan pesan dari bahasa sumber (Bsu) ke dalam Bahasa sasaran (Bsa), istilah keakuratan pemindahan pesan dar Bsu ke dalam Bsa menjadi hal yang penting. Apabila pesan dari Bsu tidak tersampaikan secara utuh ke Bsa dapat diartikan bahwa terjemahannya tidak atau kurang akurat. Nida dan Taber (1982:1) meyakini bahwa keakuratan terjemahan ditentukan oleh apakah pembaca terjemahan memahami pesan secara akurat seperti yang dimaksudk n oleh penulis aslinya. Seperti yang disebutkan oleh Kridalaksana (1985) dalam Nababan (2013:19) bahwa penerjemahan sebagai proses penyampaian amanat, sehingga seharusnya amanat tersebut dapat disampaikan secara utuh, akurat, tanpa ada pengurangan ataupun penambahan. Dapat disimpulkan bahwa keakuratan adalah pemindahan pesan semirip mungkin dari Bsu ke dalam Bsa.

Dalam menilai keakuratan terjemahan, Pelawi menggunakan Instrumen Penilai Tingkat Keakuratan Terjemahan (tabel 1) berikut.

\section{Ungkapan Budaya}

Newmark

(1988:94)

mengungkapkan bahwa budaya merupakan pandangan hidup atau cara hidup masyarakat dan manifestasinya yang menggunakan bahasa sebagai media ekspresinya. Newmark (1988:95), membagi kata-kata budaya menjadi beberapa kategori, yaitu: 1) Ecology (Flora, fauna, winds, plains, hills, honeysuckle, downs, sirocco, tundra, 
pampas, tabuleiros, plateau), 2) Material Culture: (Artifact); (food: zabaglione, sake, kaiserrschmarren); (clothes: anorak, kanga (Afrika), sarong (South East), dhoti (India); (Houses and towns: kampong, bourg, bourgade, chalet, low-rise, tower, mansion); (Transportation: bike, rikshaw, moulton, cabriolet, tilbury, caleche. 2) Social Culture (work and leisure): ajah, amah, condotirre, biwa, sithar), 3) Organisations, customs, activities, procedures, concept (political and administrative, religious, artistic), and 4) Gestures and habit.

Tabel 1. Instrumen Penilai Tingkat Keakuratan Terjemahan (Pelawi, 2014)

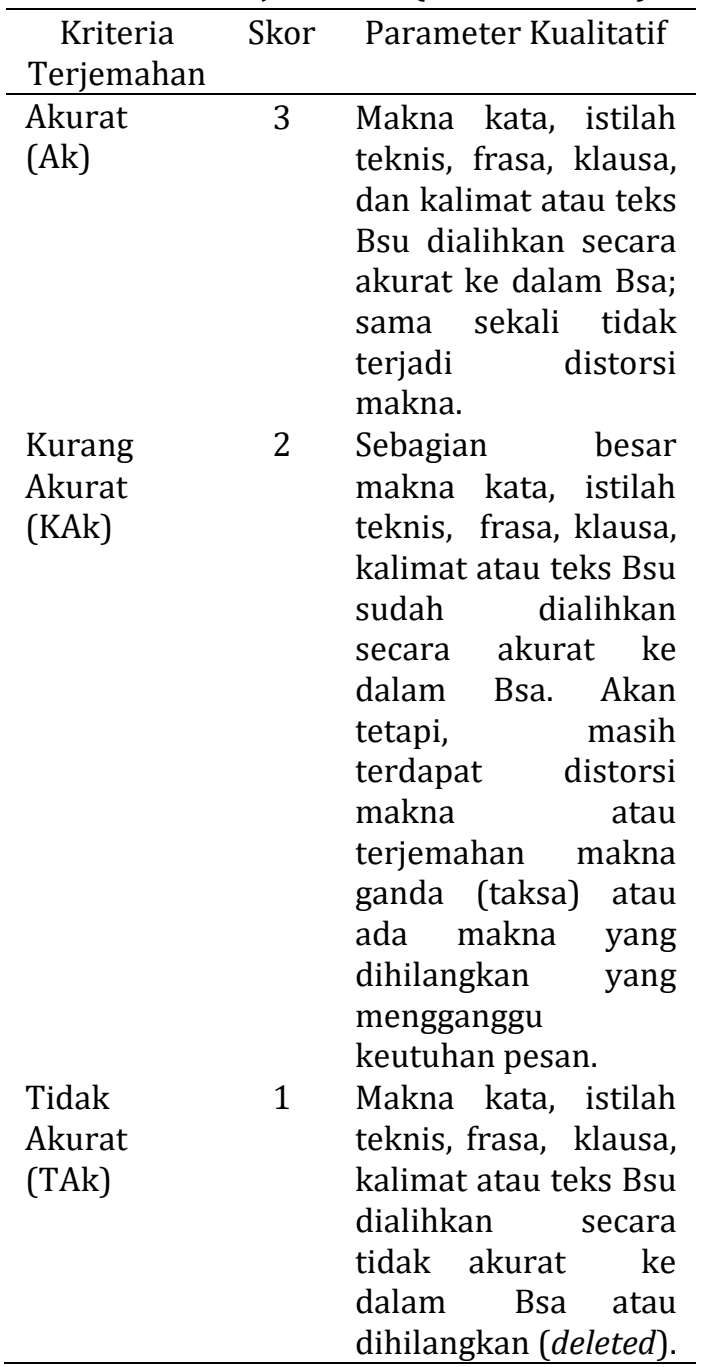

Penerjemahan tidak dapat terlepas dari budaya Bsu karena menerjemahkan bahasa berarti menerjemahkan budaya. Proses pembentukan bahasa dihasilkan oleh kebudayaan dimana bahasa tersebut berada, sehingga suatu bahasa merupakan bentuk manifestasi budaya yang berbentuk struktur bahasa (jenis kelamin dari nomina tak bernyawa), bentuk sapaan (seperti Bapak, Ibu, Mister, Sir, dan lain-lain), juga leksis ("the sunsets") (Newmark, 1988:95). Oleh karenanya, bahasa akan memiliki arti apabila bahasa tersebut berada di dalam kebudayaannya. Dengan demikian, jelas terlihat bahwa proses penerjemahan tidak hanya merupakan aktifitas bilingual tetapi juga sebagai aktifitas bikultural (Mohanty, 1994:25).

Menerjemahkan kata-kata budaya satu ke dalam kata-kata budaya yang lain akan menemui banyak permasalahan, karena bahasa memiliki makna apabila berada dalam kebudayaan yang mewadahinya. Terlebih lagi apabila budaya Bsu sangat berbeda dengan budaya Bsa. Newmark (1988:94) berpendapat bahwa menerjemahkan kata budaya tidak akan terlepas dari adanya "gap" kebudayaan atau „distance" antara Bsu dan Bsa. Oleh karenanya, seorang penerjemah harus memiliki kompetensi bahasa dan kompetensi budaya Bsu dan budaya Bsa. Selain itu, seorang penerjemah juga harus memiliki kemampuan untuk menetukan teknik penerjemahan apa yang akan digunakannya untuk menerjemahkan kata budaya sehingga didapatkan terjemahan kata budaya yang akurat dan berterima. Hal tersebut telah disampaikan oleh Nida (1975:130) bahwa ".....translators are permanently faced with the problems of how to treat the cultural aspects implicit in a source text (SL) and finding the most appropriate technique of 
successfully conveying these aspects in the target language (TL)". Dengan kata lain, keberhasilan penerjemahan kata budaya ditentukan oleh kompetensi penerjemah dan keputusan penerjemah dalam menggunakan teknik terjemahan yang tepat.

\section{METODE}

Penelitian ini merupakan penelitian pustaka dengan content analysis dengan sumber data novel The Maze Runner versi bahasa asli (Bahasa Inggris) oleh James Dashner sebagai teks sumber (TSu) dan terjemahan (Bahasa Indonesia) oleh Yunita Candra sebagai teks sasaran (TSa). Purposive sampling digunakan dalam pengumpulkan data. Didapat 11 data berupa ungkapan budaya berdasarkan kategori yang digunakan oleh Newmark (1988:95) dan Pelawi (2014) yaitu akurat (Ak), Kurang Akurat (KAk), dan Tidak Akurat (TAk). Setelah dipilih 11 data tersebut, disebarkan angket untuk menguji Instrumen Penilai Keakuratan Terjemahan. Angket tersebut diberikan kepada 12 orang teknisi penerjemah yang minimal telah menjadi penerjemah selama satu tahun. Selanjutnya, untuk menentukan keakuratan terjemahan digunakan rujukan Cambridge Dictionary, Oxford Dictionary dan Kamus Besar Bahasa Indone sia (KBBI).

\section{HASIL DAN PEMBAHASAN \\ Hasil}

Di dalam novel The Maze Runner, teknik penerjemah yang sering digunakan adalah teknik peminjaman istilah budaya (borrowing) dari Bsu, baik peminjaman alami (naturalized borrowing) maupun peminjaman murni (pure borrowing) ke Bsa. Teknik peminjaman istilah budaya dapat ditemukan pada data istilah budaya yang berhubungan dengan ekologi. Sebagian besar data istilah budaya ditemukan telah diterjemahkan secara (Ak), sebagian lagi (KAk), dan bagian terkecil (TAk).

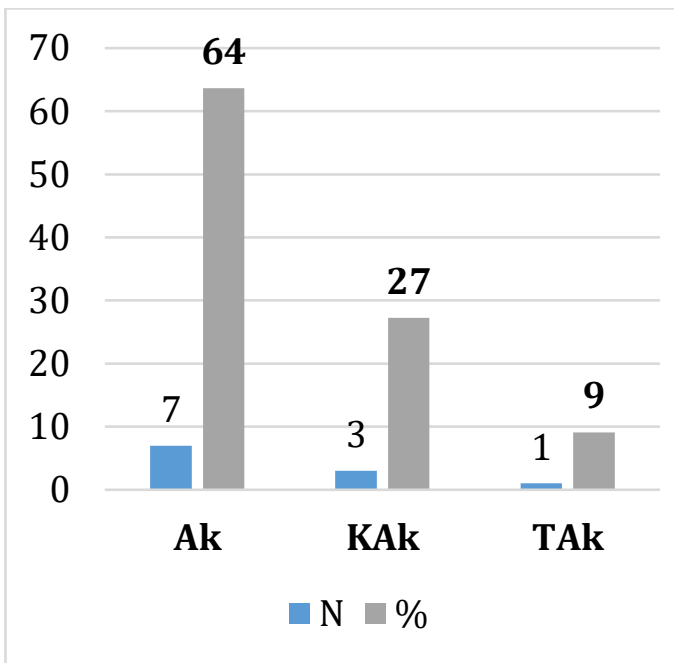

DIAGRAM 1. Frekuensi hasil terjemahan ungkapan budaya dalam Novel The Maze Runner ke dalam Bahasa Indonesia.

DIAGRAM 1 menunjukkan bahwa semua kategori terjemahan yaitu (Ak), (KAk) dan (TAk) ditemukan dalam terjemahan ungkapan budaya dalam Novel The Maze Runner ke dalam Bahasa Indonesia. Seperti terlihat pada diagram tersebut, sebagian besar, atau dua per tiga, ungkapan budaya telah diterjemahkan dengan akurat. Ungkapan budaya yang tidak diterjemahkan dengan akurat hanya sebagian kecil saja, yaitu "ham". Ungkapan-ungkapan budaya yang diterjemahkan dengan kurang akurat mencapai kurang lebih seperempat.

$$
\text { "ivy" }
$$

Tsu : The boys decided to take their lunches to eat outside, and a few minutes laterthey found them selves at 
the west wall, looking out at the many work activ itie s going on throughout the Glade, their backs up against a spot of thick ivy. (176-177)

Tsa

: Kedua anak laki-

laki itu memutuskan menyantap makan siang mereka di luar, dan beberapa menit kemudian mereka telah duduk di dekat tembok barat, memandangi berbagai aktivitas pekerja di seluruh Glade, bersandar di rumpun tanaman ivy yang tebal.

Konteks : Alby mengalami fase

Perubahan setelah disuntik serum .

Ketika seorang Glader mengalami fase perubahan, dia akan mengingat semua hal tentang masa lalunya sebelum dia tinggal di Glade. Ketika dia mencoba mengungkapkan fakta mengenai hal tersebut kepada Glader lainnya, dia akan mengalami hal yang aneh, yaitu dia akan mencoba membunuh dirinya sendiri. Ketika Alby hendak menyampaikan fakta-fakta yang dia ketahui saat dia mengalami fase Perubahan kepada New dan Thomas, tiba-tiba tangannya mencoba mencekik lehernya sendiri. New dan Thomas terkejut atas kejadian yang menimpa Alby. Mereka meninggalkan Alby dan mencari makanan untuk makan siang kemudian mereka duduk bersadar di tanaman ivy.

Ivy yang memiliki nama Latin Hedera Helix dan dari kelas tanaman Araliaceae (Ginseng family) merupakan tanaman gantung, tanaman hias dan tanaman merambat yang dapat hidup abadi (www.nps.gov). Tanaman ini dapat ditemui di Eropa (Scandinavia, Rusia), Amerika Timur dan Barat, Asia Barat dan Afrika Utara (www.nps.gov; www.missouribotanicalgarden.org; www.rhs.org.uk). Menurut Cambridge Dictionary, ivy diterjemahkan sebagai "an evergreen (=never losing its leaves plant which often grows up trees or buildings)". Tanaman ini seringkali disebut sebagai English ivy. Oxford Dictionary mendefinisikan ivy sebagai " $A$ woody evergreen Eurasian climbing plant, typically having shiny, dark gre en fivepointed leaves."

Menurut hasil perhitungan statistik, 75\% responden menyatakan bahwa data (1) merupakan data ungkapan budaya yang (Ak). Dalam data (1), ungkapan budaya thick ivy diterjemahkan menjadi tanaman ivy yang tebal. Penggunaan istilah tanaman ivy seperti pada data (1) merupakan peminjaman istilah dari Tsu, dimana teknik penerjemahan yang digunakan yaitu peminjaman murni (pure borrowing). Meskipun di dalam Tsa, ivy sering kali disebut dengan English ivy, namun penggunaan istilah tanaman ivy dirasa telah akurat karena pesan yang tersampaikan utuh, tidak mengalami distorsi makna. Penulisannya pun dimiringkan sehingga menunjukkan bahwa kata tersebut merupakan kata pinjaman.

(2) "oak"

Tsu : He stepped around a

large oak and pulled up short.

Tsa

: Dia menapak

mengelilingi sebatang pohon oak besar dan berhenti.

Konteks : Thomas memutuskan mengelilingi Glade sendirian untuk mengenal Glade lebih dalam . Dia mengelilingi setiap sudut Glade, hingga dia tiba di sudut barat daya, di dekat hutan. Saat dia sedang berjalan, dia menemukan makhluk semacam serangga mesin yang merupakan matamata para Kreator. Thomas berlari mengejar serangga mesin ters but hingga tanpa dia sadar dia sudah masuk 
ke dalam hutan yang dipenuhi dengan pepohonan yang tumbuh rapat sehingga tidak memungkinkan matahari masuk ke dalamnya. Serangga mesin itu melompat ke atas sebuah pohon yang besar dan memanjat batangnya, dan kemudian lenyap masuk ke balik dedaunan lebat. Tiba-tiba sebatang ranting bergerak di sebelah kanannya, dia mencoba melihat siapakah itu, namun tidak ada seorangpun di sana. Dia terus berjalan hingga akhirnya tiba di lapangan terbuka yang digunakan sebagai pemakaman.

Oak merupakan pohon besar yang biasanya dapat ditemui di negaranegara utara, dimana kayunya dapat digunakan untuk membuat bangunan, kapal, meja, kursi, lemari (Cambridge Dictionary; Oxford Dictionary). Di Indonesia, pohon ini jarang ditemui bahkan hampir tidak pernah ditemui, sehingga sangat jarang masyarakat Indonesia yang mengenal dan melihat secara langsung pohon ini. Dalam menerjemahkan data (2), penerjemah melakukan peminjaman istilah dan memiringkan istilah tersebut dalam penulisannya untuk menunjukkan bahwa istilah tersebut merupakan istilah pinjaman. Teknik penerjemahan yang digunakan yaitu peminjaman murni (pure borrowing). Di dalam bahasa Inggris, pohon ini memang dikenal sebagai pohon oak, namun di Indonesia, pohon oak lebih banyak dikenal sebagai pohon ek dimana istilah ek merupakan pinjaman dari Bahasa Belanda dari kata eik. Meskipun demikian, penggunaan istilah pohon oak pada data (2) dinilai telah (Ak), dimana tidak terjadi distorsi makna, makna dari Tsu tetap utuh. Hal ini dibuktikan dengan hasil perhitungan statistik, 58,33\% responden menyatakan setuju bahwa terjemahan data (2) (Ak).
(3) "apricot"

Tsu : Weeding, pruning an

apricot tree, planting squash and

zucchini seeds, picking veggies. (104)

Tsa : Menyiangi,

memangkas pohon aprikot,

menanam biji labu dan mentimun,

memetik sayuran. (134)

Konteks : Setiap Glader di Glade memiliki tugas masing -masing, seperti menjadi pelari, pengawas kebun, pemungut, anak medis. Seorang pendatang baru akan melakukan semua pekerjaan yang ada di Glade hingga dia menemukan kesukaannya atau pekerjaan yang cocok dengan keahliannya. Hari itu, Thomas mendapatkan tugas untuk menjadi tukang kebun bersama Zart yang merupakan Pengawas Kebun. Dia ditugaskan untuk menyiangi, memangkas pohon aprikot, menanam biji labu dan mentimun, memetik sayuran.

Data (3) merupakan ungkapan budaya yang berhubungan dengan ekologi dimana aprikot memiliki nama latin Prunus Armeniaca L. dan masuk dalam keluarga Rosaceae (www.fruitcrops.com). Aprikot berasal dari timur laut Tiongkok (di area Tembok Besar Tiongkok) dan dekat dengan perbatasan Rusia-Tiongkok (www.fruit-crops.com). Meskipun berasal dari Tiongkok, pohon aprikot sudah mulai dibudidayakan sejak ribuan tahun lalu dan telah menyebar ke seluruh belahan bumi. Pohon aprikot dapat dibudidayakan di kebun maupun ditanam di dalam pot dikarenakan ukurannya yang relatif kecil dan medium, dimana tingginya sekitar $3,7 \mathrm{~m}$ hingga 13,7 m (www.fruit-crops.com). Pohon aprikot dewasa akan menghasilkan bunga yang mekar pada bulan Februari dan awal Maret dan menghasilkan buah yang dapat dipanen pada akhir Juni dan Juli 
(Vossen et al.).

Di Indonesia, pohon aprikot sudah banyak dijual di pasaran dan sudah banyak dibudidayakan. Istilah aprikot sendiri sudah banyak didengar dan dikenal oleh masyarakat walaupun terkadang beberapa masih belum pernah melihat pohon maupun buah aprikot secara langsung. Dalam data (3), penulisan istilah aprikot dimiringkan oleh penerjemah. Walaupun istilah ini sebenarnya sudah banyak dikenal dan digunakan oleh masyar akat Indonesia, penulisannya masih tetap dimiringkan dikarenakan istilah ini belum diserap ke dalam Bahasa Indonesia. Hal ini dapat dibuktikan melalui KBBI, istilah aprikot ini belum dapat ditemui di dalam KBBI. Dapat dikatakan bahwa data (3) telah diterjemahkan dengan (Ak) dengan menggunakan teknik peminjaman alami (naturalized borrowing) dimana kata dari Tsu di sesuaikan dengan ejaan dari Tsa yaitu apricot menjadi aprikot.

(4) "hamburger"

Tsu : He pictured snow on trees, running down a leaf-strewn road, eating hamburger, the moon casting a pale glow on a grassy meadow, swimming in a lake, a busy city square with hundreds of people bustling about their bisiness. (1-2)

Tsa : Dia dapat membayangkan salju di puncak pepohonan, berlari di atas jalan yang bertaburan daun gugur, menyantap hamburger, sinar bulan yang berkilau pucat di atas padang rumput, berenang di danau, sudut kota yang sibuk dipadati ratusan orang yang bergegas dengan urusan masing-masing.

Konteks : Thomas memulai kehidupan barunya, yang diselimuti kegelapan yang dingin dan udara yang pengap serta berdebu. Thomas sedang berada dalam kotak gelap dan dia tidak tahu dia berada dimana. Dia hanya dapat $\mathrm{m}$ engingat namanya, "Thomas". Dia tidak dapat mengingat apapun tentang kehidupannya seperti ibunya, maupun ayahnya. Meskipun demikian, dia dapat membayangkan kenangankenangan hidupnya, seperti dia dapat membayangkan salju di puncak pepohonan, berlari di atas jalan yang bertaburan daun gugur, menyantap hamburger, sinar bulan yang berkilau pucat di atas padang rumput, berenang di danau, sudut kota yang sibuk dipadati ratusan orang yang bergegas dengan urusan masing-masing.

Hamburger merupakan makanan dari Amerika dan Eropa yang berupa daging dipipihkan, diberi selada, bawang bombai dan diberi saus dan mayones kemudian diapit di antara roti bundar. Menurut Cambridge Dictionary, Inggris Raya (UK) dan Amerika Serikat (USA) berbeda dalam mendefinisikan hamburger. Hamburger/ beefburger/ burger (informal) di UK memiliki definisi " round flat shape made of beef, which is fried and eaten between tw o halves of a bread roll". Berbeda halnya dengan USA yang mendefinisikan burger sebagai “ beef that is cut into very small pieces, used to make hamburgers".

Di Indonesia, hamburger sudah banyak dikenal masyarakat dan telah menjadi makanan favorit. Dalam menerjemahkan hamburger, penerjemah menggunakan teknik peminjaman murni (pure borrowing). Istilah hamburger dapat ditemukan di KBBI, dimana istilah hamburger didefinisikan sebagai "daging cacah (biasanya daging sapi, tetapi kadangkadang juga daging lain) yang dibentuk bulat, kemudian dipipihkan dan digoreng dengan mentega atau 
dipanggang di atas bara, biasanya dimakan sebagai isi roti bulat, diberi daun selada, saus tomat, dan bumbu lainnya". Penulisan kata hamburger juga tidak perlu dimiringkan karena telah diserap ke dalam bahasa Indonesia. Dengan demikian, data (4) dapat dikatakan (Ak) karena pesannya telah tersampaikan dengan sempurna.

$$
\begin{aligned}
& \text { a) “ham", b) “cheese", c) } \\
& \text { "mayonnais } \\
& \text { e" }
\end{aligned}
$$

Tsu : The wonderful tastes of ham and cheese and $m$ ayonnaise filled his mouth. (23)

Tsa : Kelezatan daging, keju, dan mayones memenuhi mulutnya. (30)

Konteks : Thomas sedang bersandar di pohon sembari menunggu Chuck.

Dia melihat ke sekeliling lapangan Glade secara seksama. Chuck datang dan memberikan jatah sandwich Thomas dan seketika itu Thomas mulai menggigit sandwic $h$-nya.

Di dalam data (5), terdapat tiga ungkapan budaya, yaitu ham, cheese, dan mayonnaise. Penerjemahan ungkapan budaya cheese (5b) dan mayonnaise (5c) dinilai telah (Ak). Berbeda halnya dengan ungkapan budaya ham (5a), penerjemahannya dinilai tida $\mathrm{k}$ akurat (TAk). Penerjemah melakukan penerjemahan dengan teknik generalisasi pada ungkapan budaya ham. Menurut Cambridge Dictionary, ham adalah "pig's meat from the leg or shoulder, prese rved with salt or smoke". Dalam budaya Tsu, masyarakat banyak yang mengkonsumsi babi, karena sebagian besar masyarakatnya merupakan non-muslim sehingga daging babi diperbolehkan untuk dikonsumsi. Di Indonesia, sebagian besar masyarakatnya merupakan muslim sehingga tidak diperbolehkan untuk mengkonsumsi daging babi. Dikarenakan di dalam data (5a), ham yang berarti daging babi, digeneralisasikan menjadi daging, sehingga terdapat penghilangan informasi. Hilangnya informasi tersebut, secara otomatis akan menimbulkan asumsi bahwa daging disini adalah daging sapi, yang biasa dikonsumsi masyarakat Indonesia. Dengan demikian, terjemahan ham (5a) mnenjadi daging sapi dirasa kurang tepat sehingga dapat dikatakan bahwa terjemahannya (TAk).

Ungkapan budaya berikutnya dalam data (5b) adalah cheese. Cheese menurut Cambridge D ictionary adalah " $A$ food made from milk, that can be either firm or soft and is usually yellow or white in colour". Di Indonesia, cheese telah memiliki padanan yaitu keju. Menurut Kamus Besar Bahasa Indonesia, keju adalah "bahan $\mathrm{m}$ akanan yang dibuat dari sari air susu melalui proses peragian yang dikeraskan (dikentalkan)". Dapat disimpulkan bahwa ungkapan budaya cheese yang diterjemahkan menjadi keju dinilai telah (Ak).

Mayonnaise (5c) menurut Cambridge Dictionary adalah " a thick creamy sauce made from oil, vinegar and the yellow part of eggs, which is usually eaten cold ". Mayonnaise biasanya dimakan bersama dengan makananmakanan seperti hamburger, pizza, kebab, kentang goreng maupun salad. Di Indonesia, mayonnaise banyak dikonsumsi masyarakat, pemerolehannya pun mudah, banyak dijual di supermarket. Dewasa ini, masyarakat juga telah banyak yang dapat melakukan pengolahan mayones sendiri. Penerjemah menerjemahkan kata mayonnaise menggunakan teknik 
peminjaman alami (naturalized borrowing) dimana kata mayonnaise disesuaikan dengan ejaan bahasa Indonesia menjadi mayones. Definisi mayones dijelaskan di dalam KBBI yaitu "saus dingin yang dimakan dengan selada, dibuat dari bahan kuning telur, garam , merica, moster, cuka, dan minyak yang dijadikan emulsi". Dengan demikian, data (5c) dianggap telah (Ak) karena penulisannya sudah sesuai dengan aturan baku Bahasa Indonesia, dan juga penulisannya tidak perlu dimiringkan.

$$
\text { (6) "sandwich" }
$$

Tsu : They made their way

directly to the kitche $n$, where,

despite

Frypan"sgrumbling, they were able to get cheese sandwiches and raw vegetables. (176)

Tsa : Mereka langsung menuju dapur dan mendapatkan beberapa sandwich keju serta sayuran meskipun ditambah gerutuan Frypan. (226)

Konteks : New dan Thomas melihat Alby yang mengalai fase perubahan dan dia berusaha mencekik dirinya sendiri. New dan Thomas terkejut atas kejadian yang menimpa Alby. Setelah memastikan keadaan Alby baik-baik saja, mereka meninggalkan Alby dan menuju ke dapur untuk mengambil sandwich dan sayuran untuk makan siang dan kemudian mereka duduk bersadar di tanaman ivy.

Data (6) merupakan istilah budaya yang berhubungan dengan makanan, yaitu sandwiches. Sandwich merupakan makanan yang terdiri dari dua lembar roti yang diisi dengan isian seperti tuna, ayam, babi, maupun isian bermacammacam selai. Cambridge Dictionary mendefinisikan sandwich sebagai "1. two pieces of bread, some times spread with cheese, salad, or meat, usually cold, vetween them: a tuna/ ham sandwich, a toasted sandwic h, a sandwich bar/box, sandwhich fillings; 2. UK (ALSO sandwic $h$ cake ) a cake consisting of two thin round layers with a filling such as cream between them". Di negara Barat, sandwich merupakan roti yang biasanya dijadikan bekal dan juga dapat dimakan untuk sarapan maupun makan siang, sedangkan di Indonesia, roti yang dilumuri dengan selai yang dimakan saat sarapan maupun dijadikan bekal juga sudah menjadi tradisi untuk sebagian orang. Hanya saja, tidak semua orang Indonesia menyebutnya sandwich. Masyarakat Indonesia cenderung menyebutnya dengan roti tawar atau roti bakar untuk roti yang dilumuri selai dan kemudian di panggang di panggangan roti maupun di atas teflon.

Sandwiches terdiri dari dua morfem, yaitu kata benda sandwich dan sufiks -es yang menunjukkan jamak. Dalam data (6), teknik peminjaman istilah digunakan dengan penulisan yang dimiringkan, dan juga sufiks -es dipadankan. Peminjaman istilah sandwiches pada Tsa data (6) dirasa mnenjadi pilihan tepat, karena komponen maknanya dapat disubstitusi secara utuh dan pembaca juga langsung dapat menangkap bahwa sandwich merupakan kata asing dengan cara penulisannya dimiringkan. Selain itu, karena di Bahasa Indonesia penanda jamak menggunakan kata beberapa, pemadanan penanda jamak pada Bahasa Inggris yaitu -es dengan kata beberapa juga telah tepat. Dengan demikian, data (6) dikatakan telah (Ak) dalam menerjemahkannya .

$$
\text { (7) "alley" }
$$

Tsu : At first, a shot of panic raced 
through him; he stepped back,worried it might be a Griever. But then two forms took shape, stum bling along the alley toward the Door. (111)

Tsa : Awalnya Thomas merasa panik; dia mundur, takut jika itu adalah Griever. Namun, kemudian dua sosok itu semakin mewujud, terpontang-panting di jalan setapak yang menuju Pintu. (143)

Konteks: Maze merupakan tempat mengerikan yang berisi makhlukmakhluk mengerikan seperti Griever dan Serangga-Mesin. Pintu-pintu Maze akan membuka di pagi hari dan menutup di malam hari. Yang boleh memasuki Maze hanyalah para pelari untuk memecahkan kode-kode yang ada di Mazedemi mencari jalan agar dapat keluar dari Glade. Para Pelari akan berangkat malam hari ketika Pintu Maze hendak menutup dan siang hari mereka biasanya telah kembali ke Glade . Siang itu, semua orang mengkhawatirkan Minho dan Alby yang tak kunjung kembali dari Maze sejak semalam. Karena adanya peraturan bahwa hanya Pelari yang bisa memasuki Maze, jadi tak seorang pun berani mencari mereka ke dalam Maze. Tibatiba, ketika Pintu Maze mulai menutup, bayangan Minho dan Alby yang sedang dibopong Minho karena sedang pingsan mulai terlihat. Mereka $\mathrm{m}$ asih berjarak beberapa meter dari ambang pintu, sedangkan pintu Maze sudah hampir menutup sempurna.

$$
\text { Berdasarkan perhitungan }
$$

statistik, 50\% responden setuju bahwa data merupakan data budaya yang diterjemahkan secara kurang akurat (KAk). Dalam data (7), penerjemah memadankan alley dengan jalan setapak. Apabila dilihat maknanya, alley berarti "a narrow road or path between buildings; a path in a park or garden, especially with trees or bushes on both sides" (Cambridge Dictionary). Dalam KBBI, jalan setapak memiliki makna "jalan kecil, sempit (dalam hutan dan sebagainya) yang hanya dapat dilalui dengan berjalan kaki". Dilihat dari definisi tersebut, alley dan jalan setapak memiliki makna yang berbeda. Alley merupakan jalan yang di kanan kirinya tumbuh tumbuh-tumbuhan atau pun di jalan yang diapit dengan bangunan, sedangkan jalan setapak, belum tentu di kanan dan kirinya tumbuh beraneka ragam tumbuhan. Karena pemadanan yang kurang tepat maka terjadi distorsi makna antara Tsu dan Tsa, data (7) dapat dikatakan bahwa ungkapan budaya tersebut (KAk).

(8) "courtyard"

Tsu : In the exact middle of courtyard, the still-gaping hole of the Box lay open, as if inviting him to jump back in and go home. (22)

Tsa : Tepat di tengahtengah lapangan, lubang lorong Kotak masih terbuka lebar, seolah mengundangnya untuk melompat ke sana dan pulang. (29)

Konteks :Thomas sedang bersandar di pohon sembari menunggu Chuck.

Dia melihat ke sekeliling lapangan Glade secara seksama. Dia melihat lubang lorong Kotak yang terbuka sehingga membuatnya ingin masuk kesana dan pulang. Kotak tersebut merupakan Kotak yang biasanya membawa pendatang baru ke dalam Glade.

Dilihat dari hasil perhitungan statistik, 66,67\% responden menyatakan bahwa terjemahan data (8) (KAk). Dalam data (8), courtyard yang menurut Oxford Dictionary adalah "An 
unroofed area that is completely or partially enclosed by the walls of buildings, typically one form ing part of a castle or large house" didefinisikan dengan sangat jelas, courtyard merupakan tanah lapang yang dikelilingi oleh tembok secara penuh maupun sebagian. Di dalam Tsa, courtyard diterjemahkan menjadi lapangan. Lapangan yang dikenal di dalam Bahasa Indonesia merupakan lahan terbuka luas yang biasanya tidak dikelilingi pagar maupun tembok, hanya saja biasanya dipenuhi oleh pepohonan di sekelilingnya.

Pemadanan courtyard dan lapangan dinilai kurang bisa mengakomodasi keseluruhan makna dari Tsu ke Tsa sehingga masih terdapat distorsi makna. Oleh karena itu, data (8) dapat dikatakan terjemahannya (KAk).

(9) "cut in half like a knife through whipped cream"

Tsu : "Oh, yeah smart guy?

I've seen the sucker's bones. Cut in

half like a knife through whipped cream. (51)

Tsa : “Oh, ya, Anak-

pintar? Aku pernah melihat tulang-

tulangnya.

Terpotong menjadi dua seperti pisau yang membelah krim . (67)

Konteks : Setiap anak maupun barang dikirim ke Glade oleh Para Kreator menggunakan Kotak. Saat ada pengiriman, alarm pemberitahuan akan berbunyi. Saat ini, suara alarm mengagetkan para Glader. Biasanya pendatang baru akan datang di hari dan jam yang sama setiap harinya, namun kali ini pendatang baru datang dua hari berturut-turut dimana hal itu baru terjadi kali ini. Semua Glader kebingungan dengan apa yang terjadi dan mereka berkumpul di depan pintu Kotak, begitu pula Thomas dan Chuck. Saat menunggu Kotak sampai di Glade, tibatiba Thomas terpikirkan untuk keluar dari Glade melalui lubang yang dilalui Kotak yang membawa seorang pendatang baru, dan dia menyampaikan idenya itu kepada Chuck. Chuck menjelaskan bahwa para Glader sudah m encoba berbagai cara, seperti ikut masuk ke dalam Kotak setelah Kotak melakukan pengantaran, melemparkan beberapa benda ke dalam lubang, bahkan ada seorang sukarelawan yang mencoba turun melalui lubang dengan menggunakan sulur tanam an ivy. Semua hal itu sudah pernah dilakukan para Glader, namun hasilnya nihil. Bahkan sukarelawan yang turun melalui lubang Kotak, saat baru turun sekitar tiga meter, tiba-tiba sesuatu menebas di udara dan membelah tubuh anak itu menjadi dua.

Data (9), "cut in half like a knife through whipped cream" diterjemahkan menjadi "Terpotong menjadi dua seperti pisau yang membelah krim". Dalam menerjemahkan ungkapan budaya data (9), penerjemah menggunakan teknik penerjemahan harfiah. Di dalam Tsu, whipped cream diterjemahkan menjadi krim, terdapat penghapusan infromasi, sehingga ketika diterjemahkan menjadi krim, menimbulkan makna ganda (taksa). Krim di dalam Tsa menimbulkan banyak persepsi, apakah krim pijat, krim pelengas, krim pelembab, krim pembersih, krim pemutih atau pun krim roti (KBBI). Akan lebih baik apabila penerjemah menerjemahkan dengan menggunakan teknik peminjaman murni (pure borrowing), dengan memiringkan kata tersebut sehingga tidak menimbulkan ambiguitas. Oleh karena penerjemahan data (9) menimbulkan makna taksa, maka penerjemahan data (9) dikategorikan 
sebagai terjemahan yang (KAk).

\section{Pembahasan}

Penelitian ini bertujuan untuk mengetahui akurasi terjemahan ungkapan-ungkapan budaya novel The Maze Runner versi bahasa asli (Bahasa Inggris) oleh James Dashner sebagai teks sumber (TSu) dan terjemahan (Bahasa Indonesia) oleh Yunita Candra sebagai teks sasaran (TSa). Hasil analisi menunjukkan bahwa dari sebelas data ungkapan budaya, ditemukan sebagian besar, sebanyak 7 atau 64 persen, telah diterjemahkan dengan (Ak). Ungkapan budaya yang telah diterjemahkan dengan (KAk) sebanyak tiga atau dua puluh tujuh persen dan hanya ada satu data ungkapan budaya yang diterjemahkan secara (TAk). Ditemukannya ungkapan-ungkapan budaya yang masuk kategori (KAk) dan (TAk) mengimplikasikan bahwa tidak mudah menerjemahkan ungkapanungkapan budaya dikarenakan budaya meskipun memiliki unsur-unsur universal, budaya juga bersifat unik sejalan dengan penelitian MichelSchertges (2019), Smirnova (2016), Jin (2010) dan Gabelica \& Popov (2020). Selain itu, jenis terjemahan, misalnya cultural translation (Nagashima, 2012).

\section{SIMPULAN DAN PENUTUP}

Berdasarkan kajian pustaka, topik penelitian akurasi terjemahan sudah sangat popular sehingga ditemukan banyak kajian dengan topik ini. Meskipun topik penelitian akurasi terjemahan sudah sangat banyak, tetapi terdapat hanya sedikit yang memfokuskan pada akurasi terjemahan ungkapan-ungkapan budaya. Penelitian ini mengkaji akurasi terjemahan Novel The Maze Runner dalam Bahasa Inggris oleh James Dashner ke dalam Bahasa Indonesia oleh Yunita Candra. Sebanyak 11 data ungkapan budaya dikumpulkan dan angket untuk mengukur akurasi disebarkan ke sebanyak 12 penerjemah yang memiliki pengalaman minimal 1 tahun. Setelah dianalisis dengan menggunakan taksonomi oleh Pelawi (2014) ditemukan terjemahan (Ak) sebanyak 7/64\%, (KAk) sebanyak $3 / 27 \%$, dan (TAk) sebanyak $1 / 9 \%$. Munculnya temuan (KAk) and (TAk) yang kalau digabung menjadi $4 / 38 \%$ menunjukkan bahwa menerjemahkan ungkapan-ungkapan budaya memang tidak mudah. Budaya pada satu sisi menunjukkan ciri-ciri universal sehingga terdapat kesamaan-kesamaan dengan budaya lain. Pada sisi lain, budaya mempunyai ciri-ciri yang khas dimiliki oleh budaya tersebut yang tidak bisa dijumpai di budaya lain manapun. Hal ini mengandung implikasi bahwa akurasi terjemahan tidak saja menuntut kompetensi linguistik tetapi juga kompetensi budaya baik sumber maupun sasaran bagi penerjemah.

\section{REFERENSI}

Barnett, G. A., Palmer, M. T., \& Al-Deen, H. N. (1984). Translation Accuracy: Using Multidimensional Scaling. Annals of the International Communication Association, 8(1), 659-677. https://doi.org/10.1080/23808985 .1984 .11678594

Candra, Y. (2015). The Maze Runner. Yogyakarta: Mizan Fantasi.

Dashner, J. (2009). The Maze Runner. US: Delacorte Press Ebook Edition.

Gabelica, C., \& Popov, V. (2020). “One Size Does Not Fit All": Revisiting Team Feedback Theories From a Cultural Dimensions Perspective. Group and Organization Management, 45(2), 
252-309.

https://doi.org/10.1177/10596011 20910859

Jin, C. H. (2010). An empirical comparison of online advertising in four countries: Cultural characteristics and creative strategies. Journal of Targeting, Measurement and Analysis for Marketing, 18(3-4), 253-261. https://doi.org/10.1057/jt.2010.18

Kridalaksana, H. (2008). Kamus Linguistik (Forth Edition). Jakarta: Gramedia Pustaka Utama.

Michel-Schertges, D. (2019). Contemporary Asian art and Western societies: cultural "universalism" or "uniqueness" in Asian modern art. Asian Journal of German and European Studies, 4(1), 1-18.

https://doi.org/10.1186/s40856019-0042-4

Nababan, M. R. (2013). Teori Mene rjemahkan Bahasa Inggris. Yogyakarta: Pustaka Pelajar.

Nagashima, Y. (2012). From "Literary Translation" to "Cultural Translation": Mori Ōgai and the Plays of Henrik Ibsen. Japan Review, 24(24), 85-104.

Newmark, P. (1988). A Textbook of Translation. China: Shanghai Foreign Language Education Press.

Nida, E. A and Taber. C. (1982). The Theory and Practice of Translation . Leiden: E.J. Brill.

Nida, E. A. (2006). Theories of Translation.

http://www.pliegosdeyuste.eu/n4p liegos/eugeneanida.pdf

Pelawi, B. Y. (2014). Dampak Teknik, Metode, dan Ideologi Penerjemahan terhadap Hasil Terjemahan Teks The Gospel According to Matthew dalam Teks Bahasa Indonesia . Disertasi. Yogyakarta: Fakultas Ilm u Budaya Universitas Gadjah Mada.

Rennie, T. W., Engova, D., \& Bates, I.
(2008). A pragmatic approach ensuring accuracy in language translation in tuberculosis research. Research in Social and Administrative Pharmacy, 4(4), 417-421. https://doi.org/https://doi.org/10. 1016/j.sapharm.2007.10.007

Smirnova, T. (2016). Sound of a Slogan: Appealing to Audiences in the Global Market. Procedia - Social and Behavioral Sciences, 236, 125-130. https://doi.org/10.1016/j.sbspro.2 016.12.049

Snyman, F. P. J., \& Naudé, J. A. (2003). The assessment of translation accuracy of the Lexica Machine Translation System. Southern African Linguistics and Applied Language Studies, 21(4), 295-306.

https://doi.org/10.2989/16073610 309486350 